REPORT FMI - 72-1

\title{
INSTITUTE OF AVIATION MEDICINE
}

(Flygmedicinska institutionen)

S-590 57 MALMSLÄTT, SWEDEN

ANTHROPOMETRY OF FLYING PERSONNEL IN THE ROYAL SWEDISH AIR FORCE

by

Bengt Andrae, M.D.

Jan Ekmark, M.D.

Hans Laestadius, M.E.

MATERIEL ADMINISTRATION OF THE ARMED FORCES

(Försvarets materielverk)

AIR MATERIEL DEPARTMENT

FLIGHT TEST CENTRE 
INSTITUTE OF AVIATION MEDICINE

REPORT FM1-72-1. September 1972.

ANTHROPOMETRY OF FLYING PERSONNEL IN THE ROYAL S!:EDISH AIR FORCE

by

Bengt Andrae, M.D.

Jan Ekmark, M.D.

Hans Laestadius, M.E.

\section{Excerpt from:}

Library translation No 1502

ROYAL AIRCRAFT ESTABLISH:MENT

September 1971

Translation from original report:

Andrae, B. Ekmark, J och Laestadius H. Kroppsmitt för flygande personal. Rapport FC AAI/001:6, Fly gmed inst 68:9, juli 1963.

Försökscentralen, 59057 Malmslätt, pp 49 . 
ROYAL AIRCRAFT EST.ABLISHMENT LIBRARY TRANSLATION No. I502

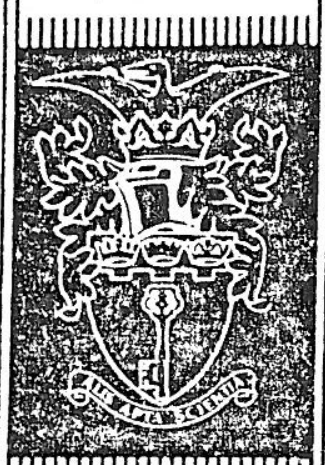

\section{ANTHROPOMETRY}

\section{OF FLYING PERSONNEL IN}

\section{THE ROYAL SWEDISH AIR FORCE}

by

B. Andrae

J. Ekmark

H. Laestadius

Institute of Aviation Medicine, Malmslatt, Sweden, Report 68:9, 1968 
Translations in this series are available from:

\author{
THE R.A.E. LIBRARY \\ Q.4 BUILDING
}

\title{
R.A.E. FARNBOROUGH
} HANTS

New translations are announced monthly in:

"LIST OF R.A.E. TECHNICAL REPORTS, TRANSLATIONS and BIBLIOGRAPHIES" 


\section{ROYAL A I R C RAFT ESTABLI SHMEN T Library Translation 1502 \\ September 1971}

ANTHROPOMETRY OF FLYING PERSONNEL IN THE ROYAL SWEDISH AIR FORCE (KROPPSMATTT FƠR FLYGANDE PERSONAL)

by
B. Andrae
J. Ekmark

H. Laestadius

Institute of Aviation Medicine, Malmslätt, Sweden, Report 68:9, 1968

Translator

F. W. Read
Translation editors

C. B. Bolton, RAE and G. M. Turner, IAM

THE NATURE OF THE WORK

To meet the current demand for information and to complete proposals begun in 'TOMT' concerning anthropometry, its equipment and cockpit space.

\section{AUTHORS' SUMMARY}

During the year 1967-8 detailed anthropometry was carried out on a total of 240 flying personnel born 1925-7, 1939-40 and 1944. Factors influencing the general growth of the body are discussed and examples given from the study of increase in stature of Swedish conscripts for military service during the last century. The measurements obtained and subsequent analysis have resulted in (i) suggested changes in standard requirements and enrolment regulations for flying personnel and (ii) recommendations concerning future measurements and pattern for experiments. 


\section{Abstract}

During the year 1967-68 detailed anthropomotry was carried out on a total of 240 flying personnel born 1925-1927, 1939-40, and 1944. Factors $i$ fluencing the general growth of the body are discussed. The report includes a longitudinal study with repeated measurements of stature and body weight at different ages of the same individual (Fig $9 \& 10$ ). The present situation as regards the body measurement of pilots is given in cumulative frequency curves (Fig 20). Stature, sitting height, eye level, and lower leg length of pilots born in 1944 in several cases show a smaller range with high mean values and fewer large values, which could mean that this age group is not yet fully grown. Certain information concerning variations in the normal male population was also obtaired. The stature of Swedish conscripts for military service during the last century shows a relatively linear growth with certain slight deviations. Based on the present authorized requirement for stature in the RSAF, on the assumption of continued stature increase in conscripts ( $1 \mathrm{~cm}$ per decade), and on the obtained mean values for pilots born 1925-27, 1939-40, and 1944 (1771, 1791, and $1797 \mathrm{~mm} \mathrm{re-}$ spectively), a mean stature of pilots in 1980 is expected to be about $1800 \mathrm{~mm}$. On enrollment of pilots it is evidently of great importance that limits for acceptable body measurements are prescribed and that these are taken into account in designing cockpit, ejection seat, apparel etc. Minimum and maximum body measurements for the year 1980 are suggested (Table 12). The measurements give only a statistical picture of body dimension development. Not until the scope and capacity for function in the cockpits of aircrafts has been analysed for various minimum and maximum sizes of pilots, can calculations be extended and estimates made of the effects of increased body size. Finally, recommendations concerning future measurements and patterns for experiments are given. 
Fig. $9 \& 10$

\section{STATURE}

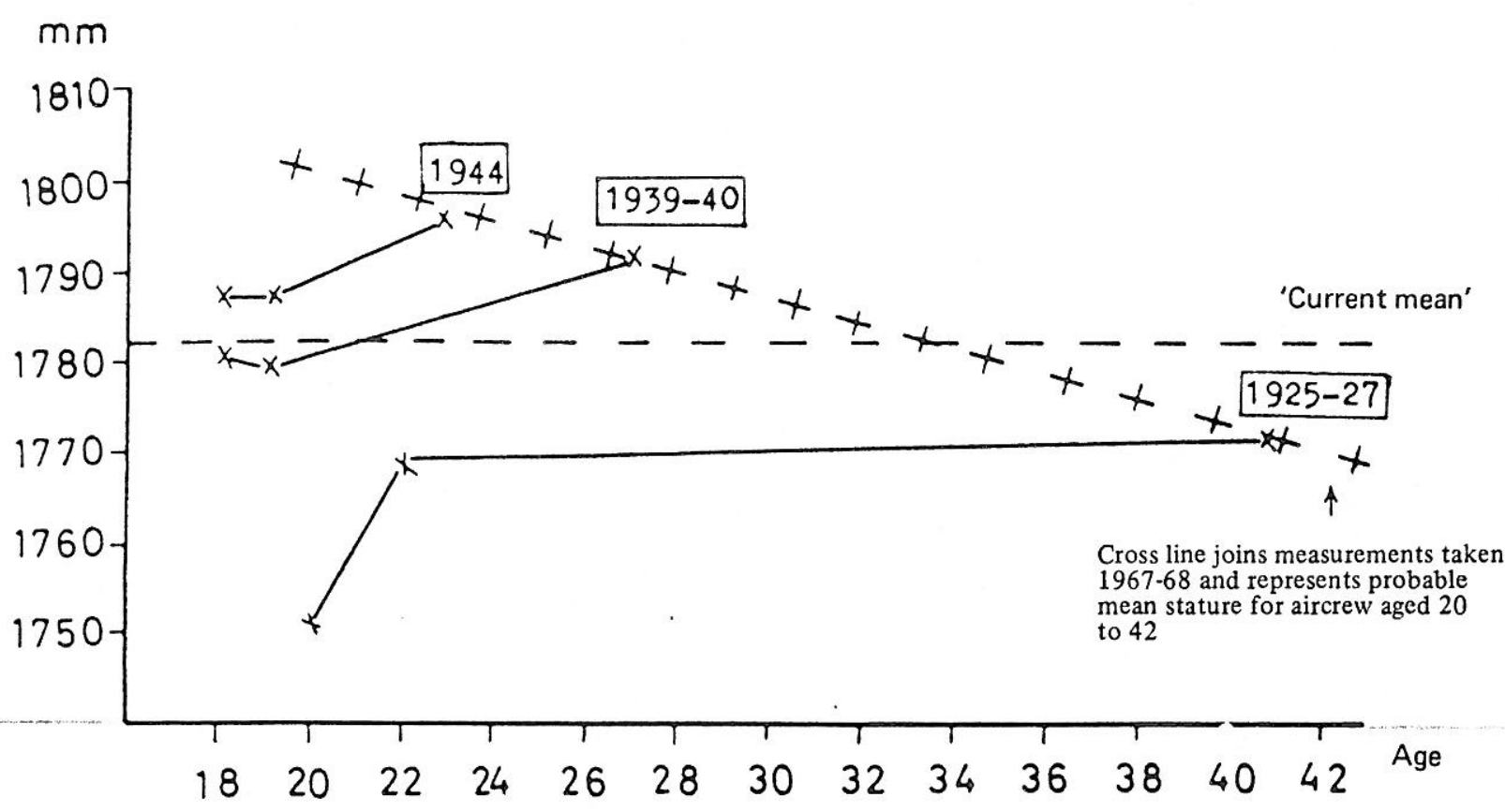

Fig. 9

WEIGHT

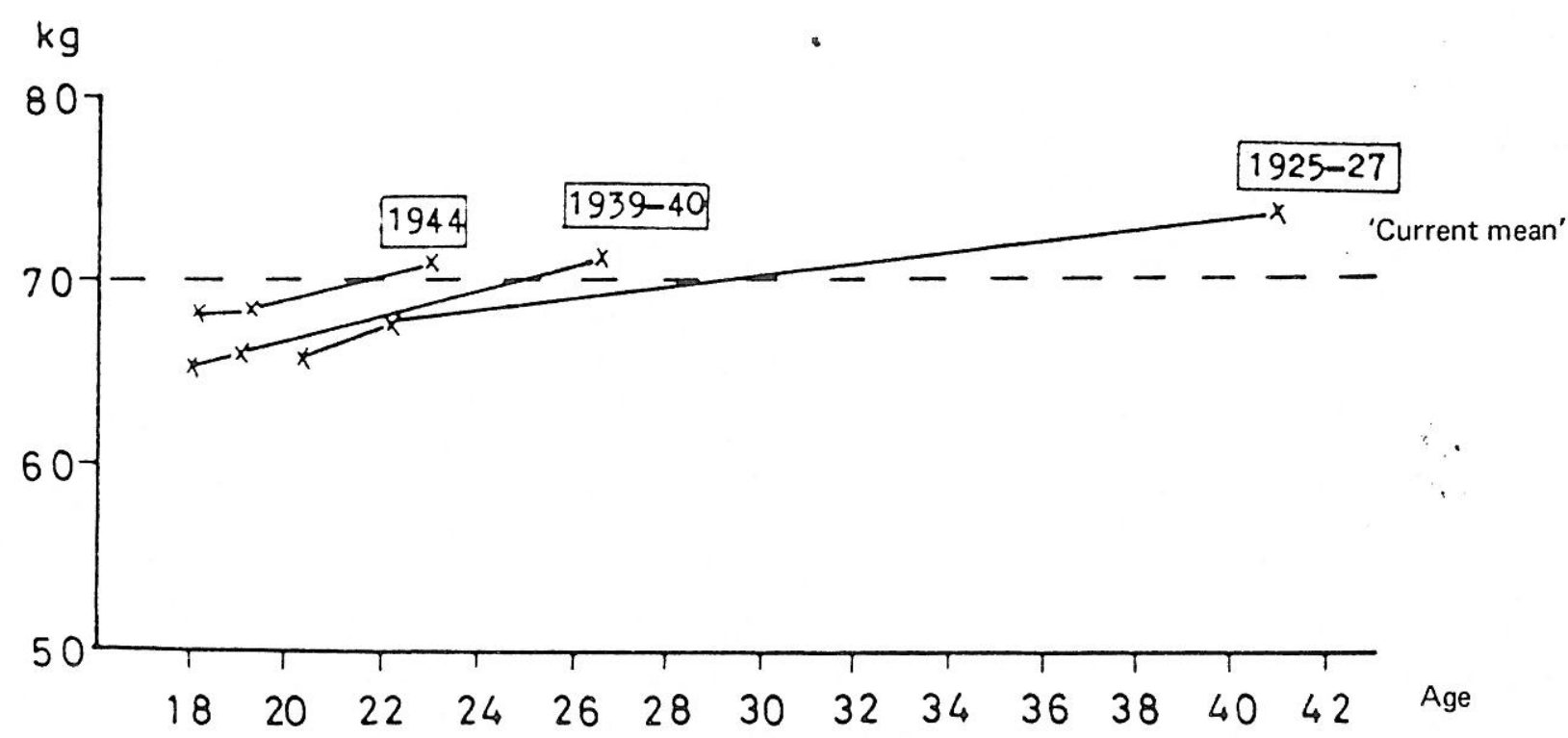

Fig.10

Fig. $9 \& 10$ 


\section{STATURE (1) $\mathrm{mm}$}

Occasion for measurement: 1967-68

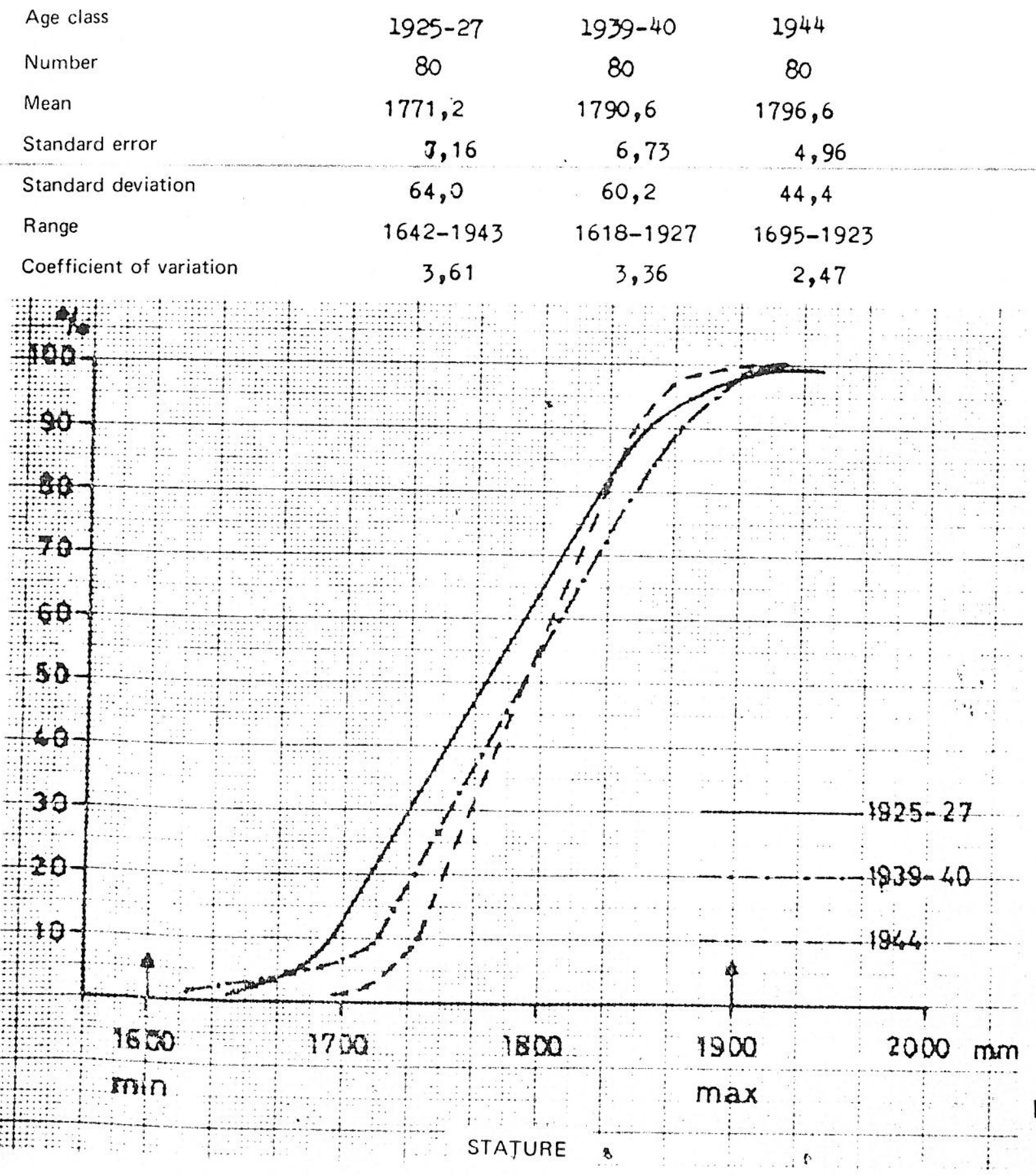

Fig.19\&20 
SUGGESTED MINIMUM, MEAN AND MAXIMUM MEASUREMENTS FOR THE YEAR 1980

\begin{tabular}{|l|r|r|r|}
\multicolumn{1}{|c|}{$\begin{array}{c}\text { Body measurement } \\
\text { (mm or kg as appropriate) }\end{array}$} & Min & Mean & Max \\
\hline Stature & 1660 & 1800 & 1960 \\
Weight & 56 & 72 & 90 \\
Sitting height & 890 & 945 & 1010 \\
Sitting eye height & 775 & 835 & 900 \\
Upper arm length & 350 & 380 & 410 \\
Elbow rest height & 200 & 250 & 300 \\
Elbow-fingertip length & 450 & 490 & 530 \\
Leg length & 1030 & 1120 & 1220 \\
Thigh bone length (Buttock-knee length) & 570 & 615 & 670 \\
Lower leg length & 520 & 565 & 610 \\
Chest depth & 190 & 225 & 265 \\
\hline Abdomen depth & 180 & 220 & 260 \\
Thigh circumference & 480 & 570 & 650 \\
\hline
\end{tabular}

